Available online on 15.03.2017 at http://jidtonline.info
Journal Of Drug Delivery and Therapeutics
Open access to Pharmaceutical and Medical research
$\begin{gathered}\text { ondisher and licensee JDDT, This is an Open Access article which permits unrestricted } \\ \text { noncommercial use, provided the original work is properly cited }\end{gathered}$

Research Article

\title{
FORMULATION AND EVALUATION OF IN-SITU NASAL GEL OF RIZATRIPTAN BENZOATE BY USING MUCOADHESIVE POLYMERS
}

\author{
Piyush Agarwal $^{1 *}$, Amit Kumar ${ }^{2}$, Y.S. Tanwar ${ }^{1}$, Shailendra Sharma ${ }^{3}$, \\ ${ }^{1}$ Bhupal Nobels College of Pharmaceutical Sciences, Udaipur, Rajasthan, India \\ ${ }^{2}$ Dept of Pharmacy, Jodhpur National University, Jodhpur, Rajasthan, India \\ ${ }^{3}$ Jodhpur Institute of Pharmacy, Jodhpur, Rajasthan, India
}

\begin{abstract}
Rizatriptan Benzoate undergo hepatic first pass metabolism. Aim of present research work is to improve bioavailability by formulating in-situ nasal gel. Formulation was developed to decrease the mucociliary authorization by using mucoadhesive polymer in gel, thus rising the contact time with nasal mucosa and humanizing the absorption of drug. Gels were primed by cold technique process and evaluate by Appearance, Viscosity, Gelation Temperature, Permeation Studies, Drug Content, Gel strength etc.. The gelation temperature of all studied gel formulations were found in range. Drug release was initiated in between $68.8-94.7 \%$ with Kpeppas best fit model. $\mathrm{pH}$ of gel was in the rang and drug content was found between 92-99.89\%. Gel strength was found in range of 20-55 sec.
\end{abstract}

Keywords: Rizatriptan Benzoate, Mucociliary, Strength

\section{Article Info}

Received Aug 20, 2016; Review Completed Sep 27, 2016; Accepted Sep 29, 2016; Available online March 15, 2017

Cite this article as:

Agarwal P, Tanwar YS, Sharma P, Batra A, Formulation and evaluation of in-situ nasal gel of Rizatriptan benzoate, Journal of Drug Delivery and Therapeutics. 2017; 7(2):132-140. DOI: http://dx.doi.org/10.22270/jddt.v7i2.1333

*Address for Correspondence

Piyush Agarwal, Bhupal Nobels College of Pharmaceutical Sciences, Udaipur, E-mail: piyush4236@gmail.com

\section{INTRODUCTION}

The bioavailability of drugs from nasal formulations depends on the physicochemical properties of drug and formulation that work together to yield optimal drug delivery across the membrane. There are certain criteria that the drug should satisfy to be distributed optimally from the nasal formulation. These are molecular weight, lipophilicity, solubility, partition coefficient and pKa.

Extent of the absorption of the drug depends on molecular weight particularly for hydrophilic compounds. The absorption of molecules less than 300 Da may not be influenced by their physicochemical properties. Nasal route is suitable for efficient delivery of the drugs up to $1000 \mathrm{Da}$. Absorption reduces significantly if the molecular weight is greater than 1000
Da except with the use of penetration enhancers. Lipophilic drugs have been found to be relatively more permeable across the nasal epithelium. Drug solubility is a major factor in determining absorption of drug through biological membranes. As nasal secretions are more watery in nature, a drug should have appropriate aqueous solubility for increased dissolution ${ }^{1,2,3}$.

The conventional drug delivery systems like solutions, suspensions and ointments, emulsions are no longer sufficient to fulfill the present day requirements of providing a constant rate delivery and prolonged time. One of the main reasons for that is poor residence time of drug at the site of action, which results into poor bioavailability. To overcome this problems gel is the dosage form to improve the residence time and increased the bioavailability ${ }^{4}$. 
Gels are defined as a substantially dilute cross-linked system, which exhibits no flow when in the steady-state. Gel state exists between solid and liquid phase. It has properties ranging from soft and weak to hard and tough.

In situ is a Latin word which means in position. In situ gel formation is a liquid formulation that generates a solid or semisolid depot after administration and shift to a gel phase when exposed to physiological conditions. This new concept of producing a gel in situ was introduced for the first time in the early 1980s. Both natural and synthetic polymers can be used for the production of in situ gels ${ }^{5.6}$.

Carbomer is high molecular weight, cross linked polyacrylic acid derivative with a strong mucoadhesive property. Carbopol being a $\mathrm{pH}$ dependant polymer is present in solution form at acidic $\mathrm{pH}$ but at alkaline $\mathrm{pH}$ forms a low viscosity gel. Carbopol polymers have very good water sorption property ${ }^{7}$. They swell in water upto 1000 times their original volume and 10 times their original diameter to form a gel when exposed to a $\mathrm{pH}$ environment above 4.0-6.0 because the $\mathrm{pKa}$ of these polymers is $6.0 \pm 0.5$.

Rizatriptan benzoate is completely absorbed following oral administration. The mean oral absolute bioavailability of the Rizatriptan benzoate tablet is about $45 \%$ and means peak plasma concentration (Cmax) reaches in approximately 1-1.5 hours (Tmax). The presence of a migraine headache did not appear to affect the absorption or pharmacokinetics of Rizatriptan benzoate. Food has no significant effect on the bioavailability of Rizatriptan benzoate but delays the time to reach peak concentration by an hour. In clinical trials, Rizatriptan benzoate was administered without regard to food. The plasma half-life of Rizatriptan benzoate in males and females averages 2-3 hours ${ }^{8-11}$.
Present study is to achieve brain targeted drug delivery of rizatriptan benzoate for patients suffering from migraine. It is a general study that tries to cover a noseto-brain pathway for drug rizatriptan benzoate, intranasal delivery, which significantly increases brain accumulation of rizatriptan benzoate and could be an effective alternative to parentral and oral formulations. The nasal ruote will be able to provide longer residence properties and hence better bioavailability of the drug. Formulation in the nasal cavity exhibited prolonged drug release characteristics with almost negligible toxic effects to the nasal mucosa. The ease of administration coupled with its ability to provide sustained release could probably result in less frequent administration, thus enhancing patient compliance.

\section{MATERIALS AND METHOD}

Rizatriptan Benzoate was obtained from M/s Torrent Pharmaceuticals Pvt. Ltd., Other chemicals and instruments were used analytical grade.

\section{METHODS}

Preparation of gels

Nasal gels were prepared using bioadhesive polymers at its optimum concentrations as determined by viscometric studies. The materials were dissolved in a measured volume of nasal solution. The insides were sonicated using Pci Ultrasonic cleaner for $10 \mathrm{~min}$ and stirred in a magnetic stirrer for $15 \mathrm{~min}$. The whole substance was sealed and stored in the refrigerator overnight to allow complete swelling. An aliquot amount of Rizatriptan Benzoate was added and stirred again for $15 \mathrm{~min}$. The prepared gel was sonicated to ensure the complete removal of air bubbles. Similarly gels were prepared using different enhancers.

Table 1: Formulation of in-situ nasal gel of Rizatriptan Benzoate

\begin{tabular}{|l|l|l|l|}
\hline Composition $(\%(w / v))$ & \multirow{2}{*}{ Rizatriptan Benzoate } & Pluronic F127 & \multirow{2}{*}{ Carbopol 934P } \\
\cline { 1 - 1 } Batch Code & & & \\
\hline F1 & 2.5 & 18 & - \\
\hline F2 & 2.5 & 18 & 0.1 \\
\hline F3 & 2.5 & 18 & 0.2 \\
\hline F4 & 2.5 & 18 & 0.3 \\
\hline F5 & 2.5 & 18 & 0.4 \\
\hline F6 & 2.5 & 18 & 0.5 \\
\hline
\end{tabular}

\section{Evaluation of Gels}

\section{Appearance}

The developed formulations were inspected visually for clarity in sol and gel form.

\section{pH of the gels}

The $\mathrm{pH}$ of the formulations was gritty by bring the electrode of the $\mathrm{pH}$ meter in contact with the surface of the formulation and allowing it to equilibrate for $1 \mathrm{~min}^{12}$, 13 .

\section{Gelation Studies}

The in situ gel forming solution and the artificial nasal fluid were mixed and the gelation was observed by visual examination. Gelation studies were carried out according to (Balasubhramanian J. et al 2003) ${ }^{14}$ in different $\mathrm{pH}$ Buffers (pH5.0, 6.0, 6.6, 7.4) and was assessed by visual examination. Gelation temperature and gel melting was assessed by a modified process ${ }^{15}$ as follow $2 \mathrm{ml}$ aliquot of gel was transferred to test tube, sealed with aluminium foil and increased in increment of $1^{\circ} \mathrm{C}$ and left to equilibrate for $5 \mathrm{~min}$ at each new setting. The samples were then examined for gelation which was said to have occurred when meniscus no longer move upon tilting through $90^{\circ} \mathrm{C}$. The gel melting 
temperature, a critical temperature when the gel starts flowing upon tilting $90^{\circ} \mathrm{C}$, was recorded.

\section{Content uniformity}

Formulations were tested for content uniformity. Bottles containing the formulation were properly shaken for 2.3 min. The formulation, $1.0 \mathrm{ml}$ was transferred into a 100 $\mathrm{ml}$ volumetric flask and $50 \mathrm{ml}$ of simulated nasal fluid was added. The formed gel was completely crushed with the help of a glass rod, followed by vigorous shaking until the formed gel got completely dispersed to give a clear solution. The volume was adjusted to $100 \mathrm{ml}$ with simulated tear fluid. The solution was filtered through a $0.45-\mathrm{mm}$ filter membrane and the drug concentration was determined with a UV-Visible spectrophotometer at $280 \mathrm{~nm}^{16,17}$

\section{Determination of Mucoadhesive Strength}

Mucoadhesive Strengths of gel was determined by using the modified method reported by Choi et $\mathrm{al}^{18}$. Nasal mucosal tissues, obtained from the local slaughterhouse, were carefully removed from the nasal cavity of goat and mounted on glass surface using adhesive tape while another mucosal section was fixed in inverted position to the cylinder. $50 \mathrm{mg}$ of gel was placed on mucosal surface. The glass mounted mucosal surface with gel formulation and mucosal surface attached to cylinder were held in contact with each other for $2 \mathrm{~min}$ to ensure intimate contact between them. In second pan, the weights were kept rising until two mucosa get detached from each other. The nasal mucosa was changed for each measurement

\section{Viscosity Measurement}

The viscosity measurements were carried out by using Brookfield DV Pro-II model with spindle No.62.The instrument was equipped with the temperature control unit and the sample were equilibrated for $10 \mathrm{~min}$ before the measurement. The viscocity was measured against increasing shear rate. Measurement was taken at $4 \mathrm{c}$ and $34^{0}$ c respectively ${ }^{19}$.

\section{In-vitro Release Studies}

The drug release of the Rizatriptan Benzoate in situ gel was measured using Franz diffusion cell. Assembly was set and the temperature was maintained at $37 \pm 0.5^{\circ} \mathrm{C}$, then $2 \mathrm{ml}$ of nasal in situ gel of Rizatriptan Benzoate in was applied in the donor compartment, which was separated by the receptor compartment with the cellophane membrane. Three $\mathrm{ml}$ aliquots of samples were withdrawn at regular time intervals and replaced with an equal volume of phosphate buffer as fresh receptor medium. The samples were appropriately diluted with Phosphate buffer and analyzed spectrophotometrically (Double beam UV-visible spectrophotometer) at $280 \mathrm{~nm}^{20}$.

\section{Drug release kinetics and mechanism:}

In order to understand the kinetic and mechanism of drug release, the result of in vitro drug release study of nasal in situ gels were fitted with various mathematical models. Based on the R2-value or n-value, the bestfitted model was selected ${ }^{21,22}$.

\section{Drug content estimation}

Each formulation $(1 \mathrm{ml})$ was taken in a $100 \mathrm{ml}$ volumetric flask diluted with distilled water and shaken to dissolve the drug. The solution was filtered through whatmann filter paper and $1 \mathrm{ml}$ of filtered solution was further diluted to $100 \mathrm{ml}$ with distilled water. Drug content was estimated spectrophotometrically by measuring the absorbance of the above solution at 280 $\mathrm{nm}^{23,24}$.

\section{RESULTS AND DISCUSSION}

\section{Mucoadhesive Polymer Formulations}

Mucoadhesive dosage forms have gained and still gaining, considerable interest as a means of providing intimate contact and prolonging the residence time of a dosage form intended for nasal and ocular administration

It generally accepted that process involves three steps; wetting and swelling of the polymer to permit intimate contact with biological tissue, interpenetration of bioadhesive polymer chains with mucin molecules leading to entanglement and formation of weak chemical bonds between entangled chains, the mechanisms by which mucoadhesion bonds form are not completely clear. There are five theories of adhesion have been developed to explain the properties of wide range of materials including glues, adhesives and paint.

\section{Evaluations of Gels}

\section{Appearance}

\section{Table 2: Appearance of gel}

\begin{tabular}{|l|l|l|}
\hline S.NO. & Formulation Code & Appearance \\
\hline 1 & C1 & Transparent solution \\
\hline 2 & C2 & Transparent \&Viscous solution \\
\hline 3 & C3 & Transparent solution \\
\hline 4 & C4 & Transparent solution \\
\hline 5 & C5 & Transparent solution \\
\hline 6 & C6 & Transparent \&Viscous solution \\
\hline
\end{tabular}

Clarity of all the formulations was found to be satisfactory.

\section{pH of mucoadhesive nasal gels}

The $\mathrm{pH}$ of the formulations was found to be satisfactory and was in the range of 4.5-5.5.

\section{Gelation Temperature}

It was previously proved that pluronics undergo thermal gelation or sol-gel transition at a temperature of about 25 to $37^{\circ} \mathrm{C}$. Below the transition temperature Pluronic solutions allow a comfortable and precise delivery in the nasal cavity where thermogelation occurs. Immediate gelling increases residence time and enhances bioavailability of drug. The gelation temperature of all batches is shown in table 3. In Pluronic gels, gelation studies in $20-24 \%(\mathrm{w} / \mathrm{w})$ concentration showed that gelation temperature decreases with increase in gel melting temperature as Pluronic concentration increases. Gelation of PF-127 was found dependent on aqueous solubility of the polymer. 
Table 3: Gelation Temperature

\begin{tabular}{|l|l|l|}
\hline S.No. & Formulation & Gelation Temp. \\
\hline 1 & F1 & $42^{0} \mathrm{c}$ \\
\hline 2 & F2 & $38^{0} \mathrm{c}$ \\
\hline 3 & F3 & $32^{0} \mathrm{c}$ \\
\hline 4 & F4 & $36^{0} \mathrm{c}$ \\
\hline 5 & F5 & $38^{0} \mathrm{c}$ \\
\hline 6 & F6 & $40^{0} \mathrm{c}$ \\
\hline
\end{tabular}

Viscosity: Viscosity measurement of the formulations at $4^{0} \mathrm{c}$ and $37^{\circ} \mathrm{c}$ temperatures showed that there was increase in viscosity with increase in temperature. This indicated the formation of temperature induced gel structure of poloxamer.in addition to this Carbopol 934 showed viscosity enhancing effect. At constant concentration, abrupt changes in viscosities were observed due to sudden rise in micellar concentration. At low temperature region the liquid shows a very slight decrease in viscosity which was attributed to the dehydration of PPO blocks of the unimers .with rise in temperature. The unimers start to form spherical micelles causing increase in intrinsic viscosity as a result of extremely high salvation in the micellar shell. At $1 \circ \mathrm{C}$ temperature increase causes $10 \%$ increase in the micellar concentration and $3.3 \%$ decrease in the intermicellar distance as well as two-fold increase in viscosity. Viscosity of all formulation at $4 \mathrm{c}$ and $37^{\circ} \mathrm{c}$ showed in table

Table 4: shows measurement of viscosity

\begin{tabular}{|l|l|l|l|}
\hline S.NO & Formulation & Viscosity $(C P)$ at 4 $^{0} \mathbf{C}$ & ${\text { Viscosity }(\mathbf{C P}) \text { at } 37^{0} \mathbf{C}}^{\mathbf{C}}$ \\
\hline 1 & F1 & 23.4 & 144 \\
\hline 2 & F2 & 33 & 947 \\
\hline 3 & F3 & 42.3 & 2879 \\
\hline 4 & F4 & 51.3 & 164000 \\
\hline 5 & F5 & 27.3 & 287.9 \\
\hline 6 & F6 & 36.9 & 1236 \\
\hline
\end{tabular}

\section{Measurement of gel strength}

It is very important that the nasal gel formulation must have suitable gel strength. The gel strength of nasal gel formulation at $37^{\circ} \mathrm{C}$, increased as the concentration of
Carbopol and Poloxamers increased The mechanism of the increase gel strength might be related to hydrogen bonding between Pluronic and bioadhesive polymers in the nasal gel.

Table 5: Measurement of Gel Strength

\begin{tabular}{|l|l|l|l|}
\hline S.N. & Formulation & Gel strength in Sec & Bioadhesive Force $\left(\right.$ Dynes $\left./ \mathrm{cm}^{2}\right)$ \\
\hline 1 & F1 & 110 & $2496.81 \pm 10$ \\
\hline 2 & F2 & 117 & $4369.42 \pm 0.113$ \\
\hline 3 & F3 & 130 & $8114.64 \pm 0.118$ \\
\hline 4 & F4 & 115 & $2746.49 \pm 0.11$ \\
\hline 5 & F5 & 120 & $3745.22 \pm 0.12$ \\
\hline 6 & F6 & 118 & $2496.81 \pm 0.12$ \\
\hline
\end{tabular}

Mucoadhesive strength was determined in term of detachment stress i.e. force required to detach the formulation from mucosal surface. Results indicated that the variation in concentration of Carbopol 934 and Poloxamers 407 showed changes in Mucoadhesive strength. The gradual increase was observed in Mucoadhesive strength as the level of Carbopol 934 increased .Our findings are similar with previously reported work with Carbopol polymer. In this review, bioadhesion was observed due to the availability of carboxyl group. Carbopol has very high percentage of $(58 \%-68 \%)$ of carboxyl group that undergoes hydrogen bonding with sugar residues in oligosaccharide chain in mucus membrane, resulting in strengthened network between polymer and mucus membrane. The stronger the Mucoadhesive force is, the more it can prevent the gelled solution coming out of the nose.

Table 6: Gelling Capacity and Drug Content

\begin{tabular}{|l|l|l|l|}
\hline S.No & $\mathrm{pH}$ & Gelling Capacity & Drug Content \\
\hline F1 & 4.2 & ++ & $98.01 \pm 0.83$ \\
\hline F2 & 4.5 & +++ & $97.19 \pm 0.92$ \\
\hline F3 & 5.0 & + & $98.51 \pm 0.13$ \\
\hline F4 & 4.2 & ++ & $97.26 \pm 0.12$ \\
\hline F5 & 5.5 & +++ & $96.54 \pm 0.98$ \\
\hline F6 & 4.8 & +++ & $98.04 \pm 0.18$ \\
\hline
\end{tabular}




\section{Drug content uniformity determination}

The percent drug content for formulations F7 to F11. The drug content was found to be in acceptable range for all the formulations. Percent drug content of formulations F7, F8, F9, F10 and F11 was found to be $91.80 \%, 98.33 \%, 99.19 \%, 97.03 \%$ and $94.09 \%$ respectively. This indicates that process employed to prepare gels in this study was capable of producing gels with uniform drug content and minimal gel variability.

\section{Drug Release}

Diffusion studies were carrying out using franz diffusion cell, F5 showed the persistent drug release. F3 showed drug release $79.76 \%$ at $8 \mathrm{hrs}$. Concentration of HPMC raise leads to decrease the drug release. Poloxamer concentration distress on drug release.

Table 7: Cumulative Drug Release

\begin{tabular}{|l|l|l|l|l|l|l|}
\hline Time (min) & \% CDR F1 & \% CDR F2 & \% CDR F3 & \% CDR F4 & \% CDR F5 & \% CDR F6 \\
\hline 0 & 0 & 0 & 0 & 0 & 0 & 0 \\
\hline 15 & 12.13 & 14.935 & 15.217 & 10.456 & 9.562 & 10.9934 \\
\hline 30 & 16.85 & 18.1264 & 16.6659 & 13.006 & 12.0156 & 13.001 \\
\hline 45 & 22.56 & 21.6749 & 21.4845 & 16.002 & 14.2212 & 15.5397 \\
\hline 60 & 28.57 & 28.123 & 25.75339 & 20.5432 & 17.1237 & 18.3132 \\
\hline 90 & 30.26 & 30.9835 & 30.3671 & 23.728 & 24.8414 & 21.8782 \\
\hline 120 & 36.57 & 39.2554 & 35.2461 & 29.123 & 29.3833 & 26.2274 \\
\hline 180 & 38.12 & 45.07651 & 41.4426 & 32.747 & 37.012 & 30.5667 \\
\hline 240 & 43.46 & 54.132 & 47.3362 & 38.4563 & 38.3215 & 35.2564 \\
\hline 300 & 63.5623 & 81.8279 & 67.779 & 58.8701 & 54.7415 & 54.45616 \\
\hline 360 & 69.12 & 83.125 & 74.1256 & 68.4589 & 64.9871 & 63.1456 \\
\hline 420 & 44.4562 & 88.125 & & 77.5045 & 72.1207 & 68.459 \\
\hline 480 & & 91.456 & & 86.1829 & 81.002 & 77.5947 \\
\hline
\end{tabular}

Figure 1: Drug Release Kinetics Zero Order Formulation

(F1)

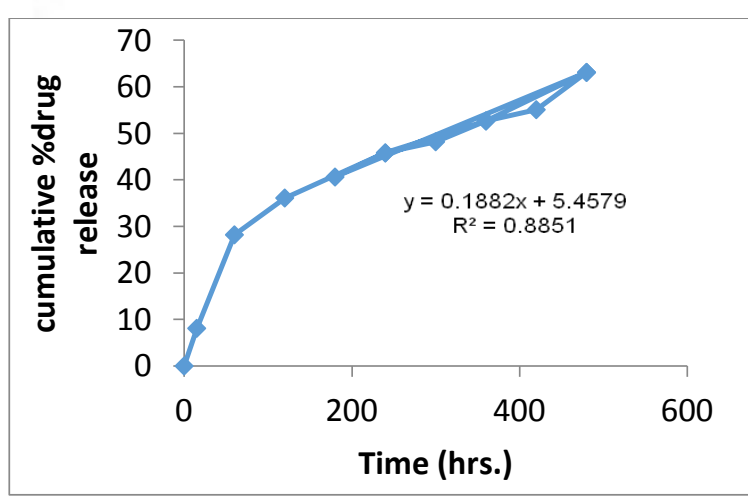

Figure 2: Drug Release Kinetics First Order Formulation

(F1)

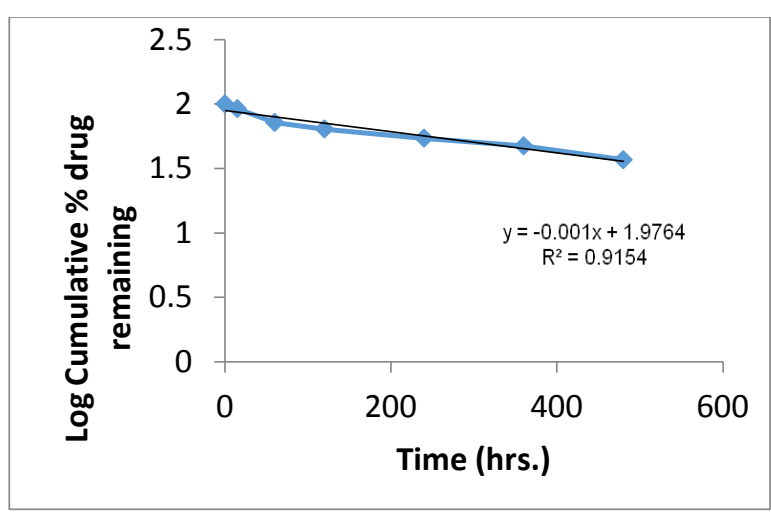

Figure 3: Drug Release Kinetics Higuchi Formulation (F1)

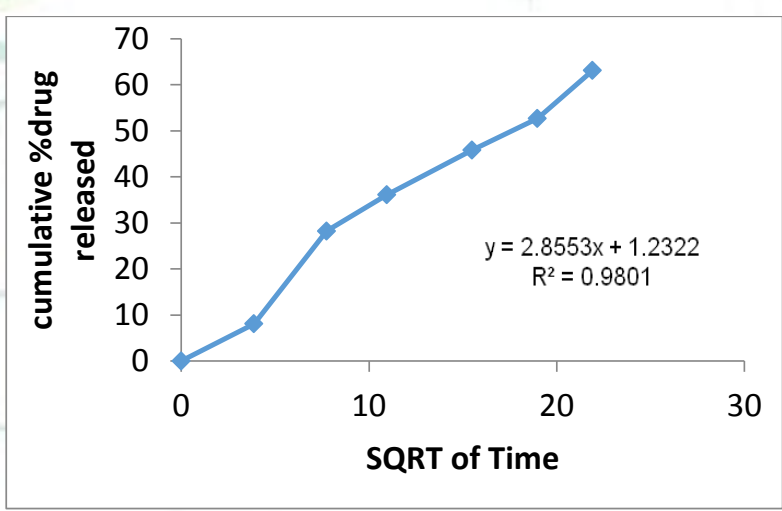

Figure 4: Drug Release Kinetics Kors - Peppas Formulation (F1)

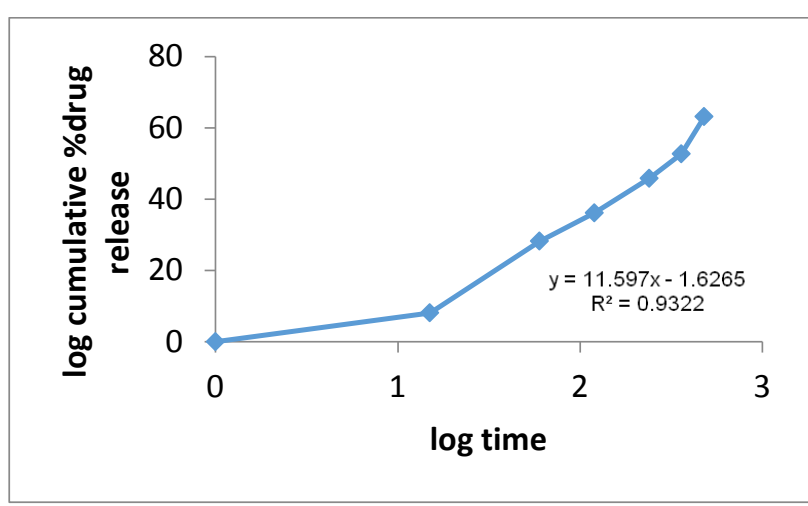


Figure 5: Drug Release Kinetics Zero Order Formulation

(F2)

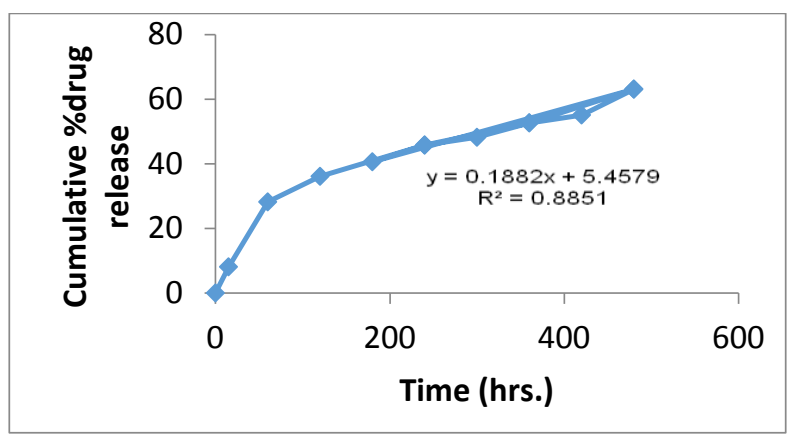

Figure 6: Drug Release Kinetics First Order Formulation (F2)

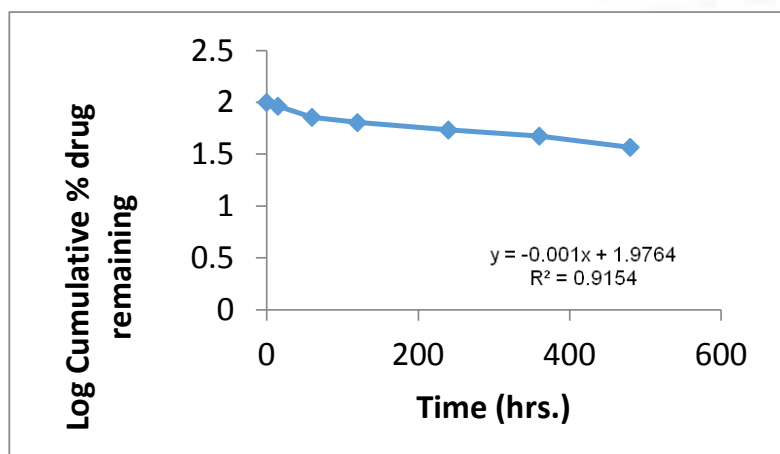

Figure 7: Drug Release Kinetics Higuchi Formulation (F2)

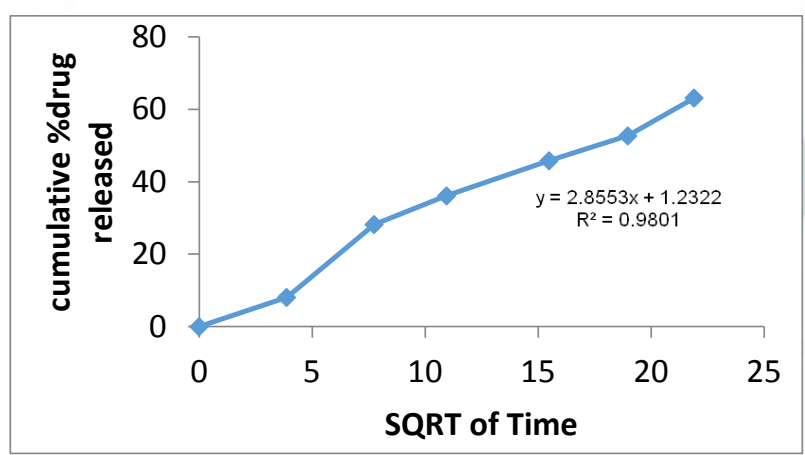

Figure 8: Drug Release Kinetics Kors-Peppas Formulation (F2)

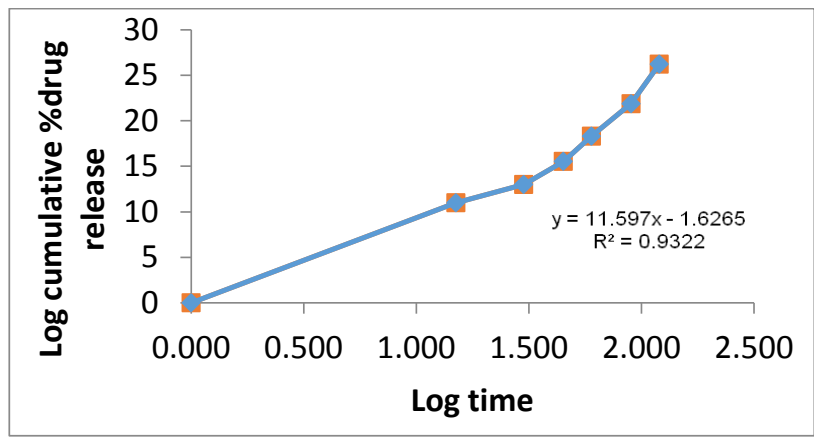

Figure 9: Drug Release Kinetics Zero Order Formulation (F3)

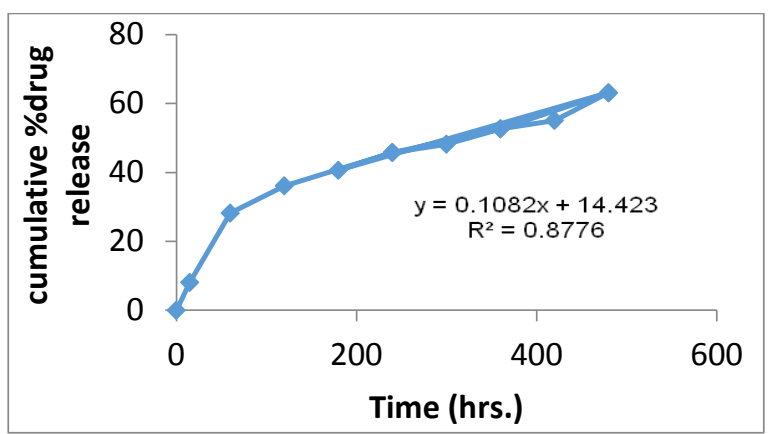

Figure 10: Drug Release Kinetics First Order Formulation (F3)

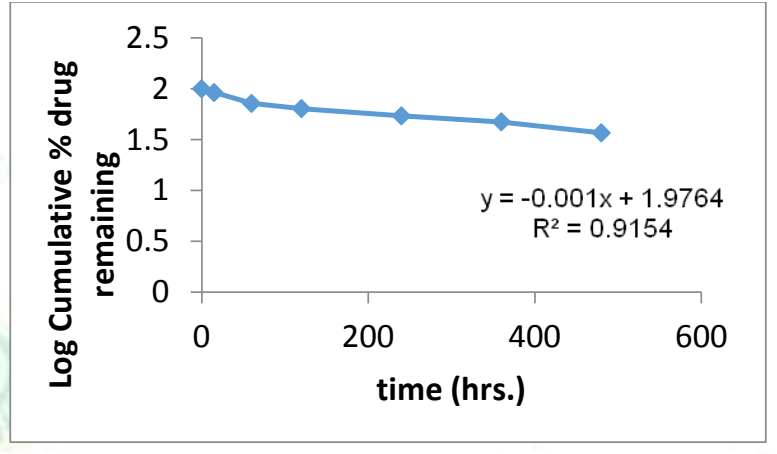

Figure 11: Drug Release Kinetics Higuchi Formulation (F3)

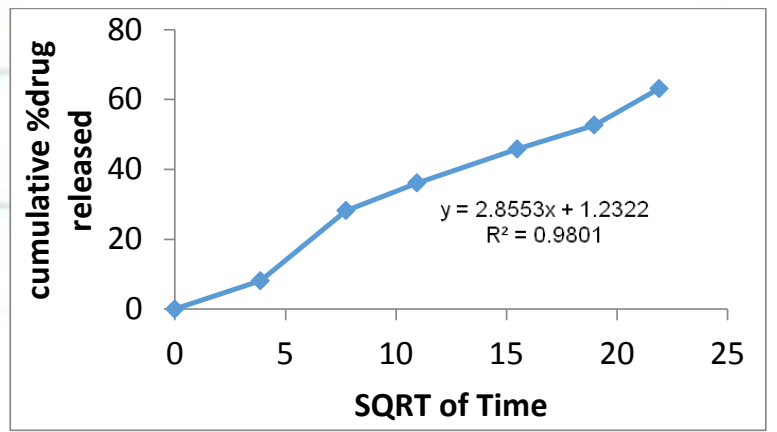

Figure 12: Drug Release Kinetics Kors-Peppas Formulation (F3)

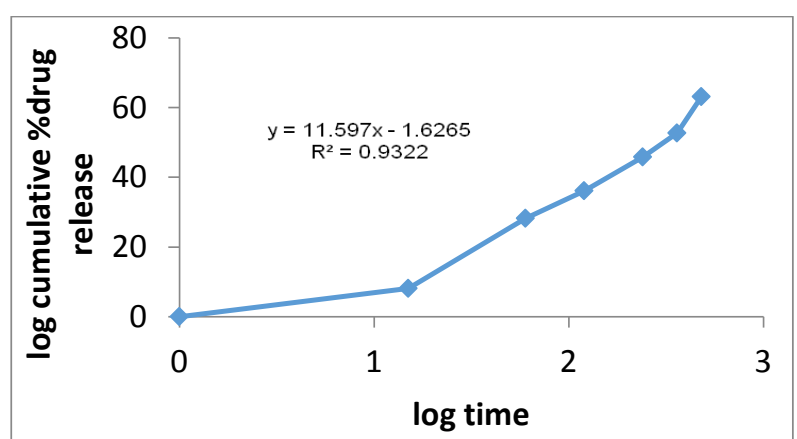


Figure 13: Drug Release Kinetics Zero Order Formulation (F4)

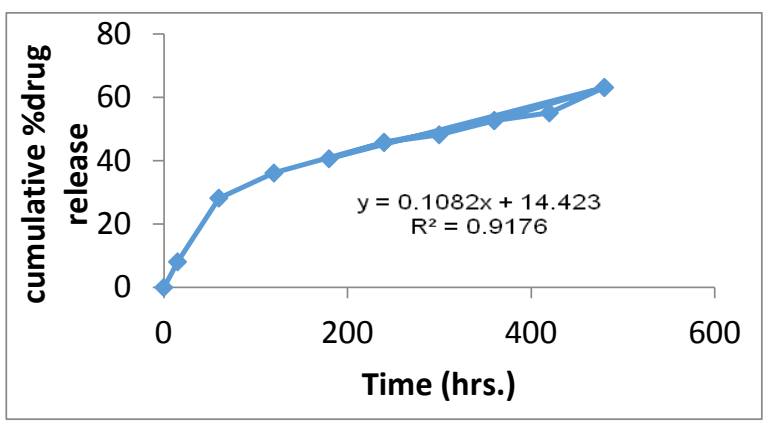

Figure 14: Drug Release Kinetics First Order Formulation (F4)

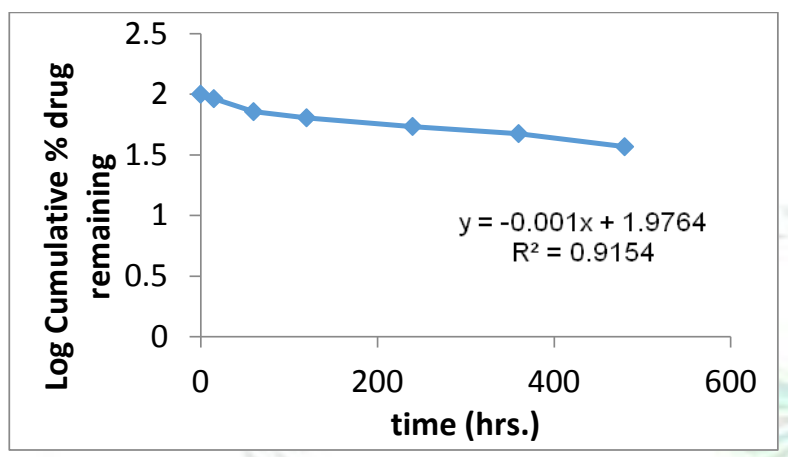

Figure 15: Drug Release Kinetics Higuchi Formulation (F4)

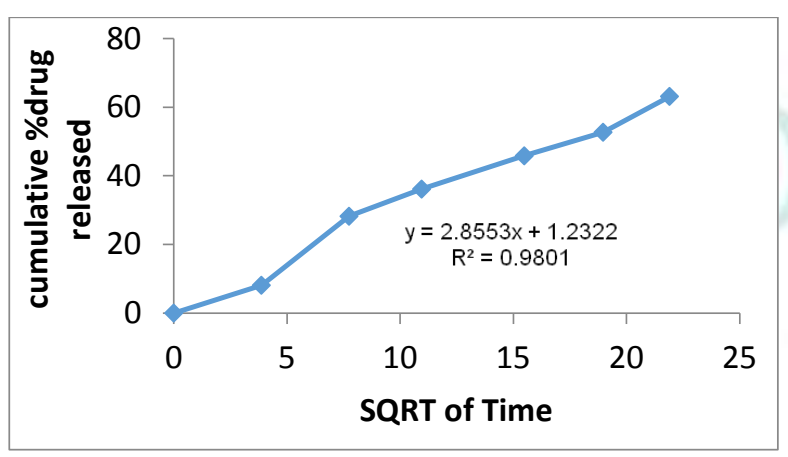

Figure 16: Drug Release Kinetics Kors - Peppas Formulation (F4)

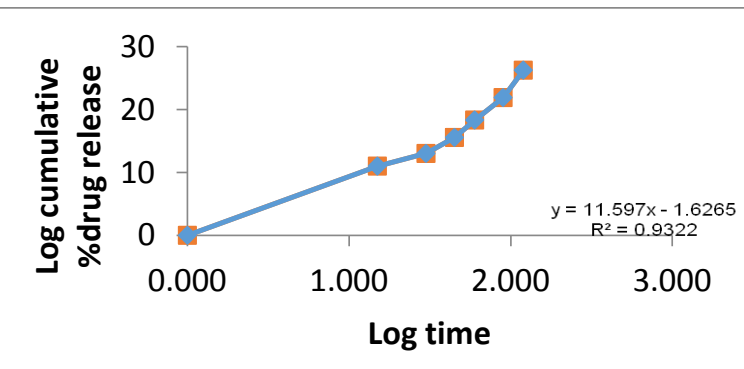

Figure 17: Drug Release Kinetics Zero Order Formulation (F5)

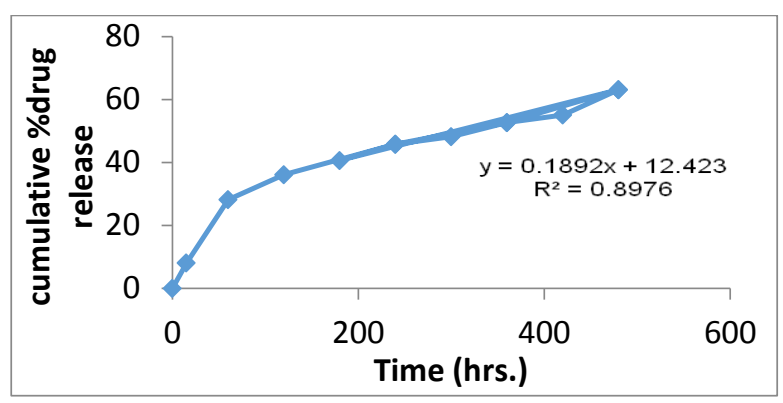

Figure 18: Drug Release Kinetics First Order Formulation (F5)

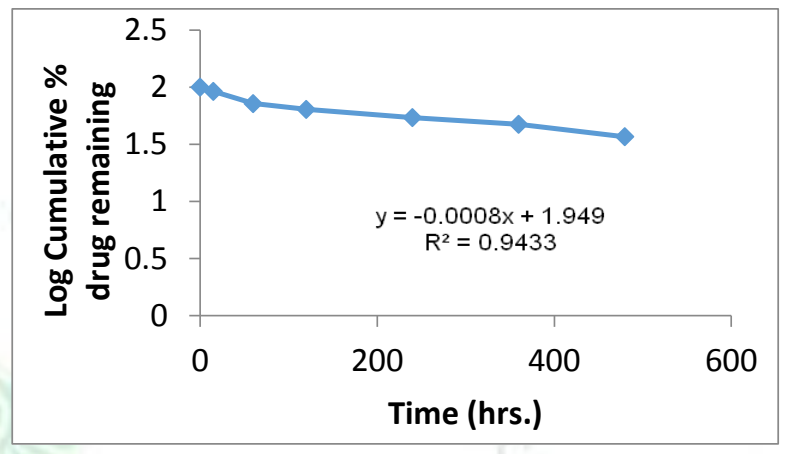

Figure 19: Drug Release Kinetics Higuchi Formulation (F5)

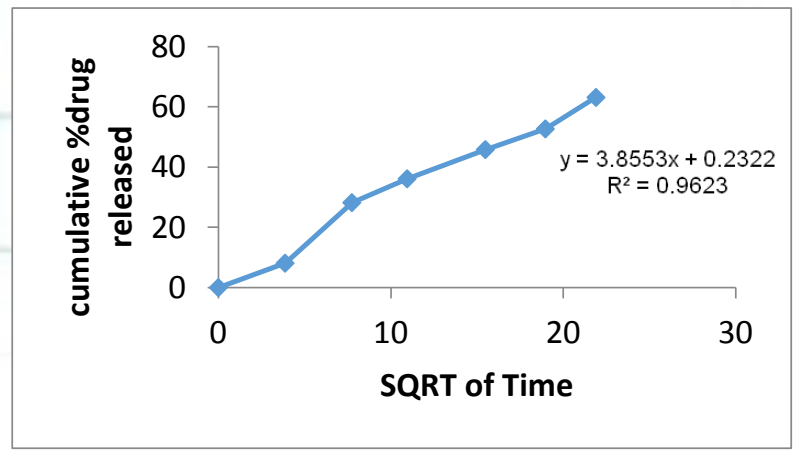

Figure 20: Drug Release Kinetics Kors- Peppas Formulation (F5)

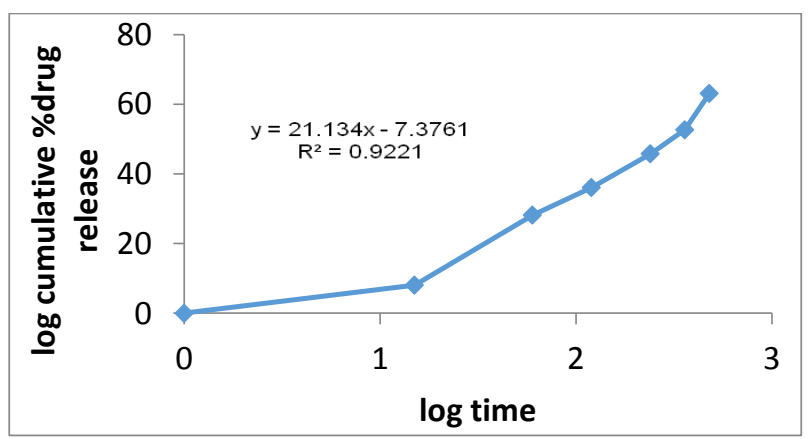


Figure 21: Drug Release Kinetics Zero Order Formulation (F6)

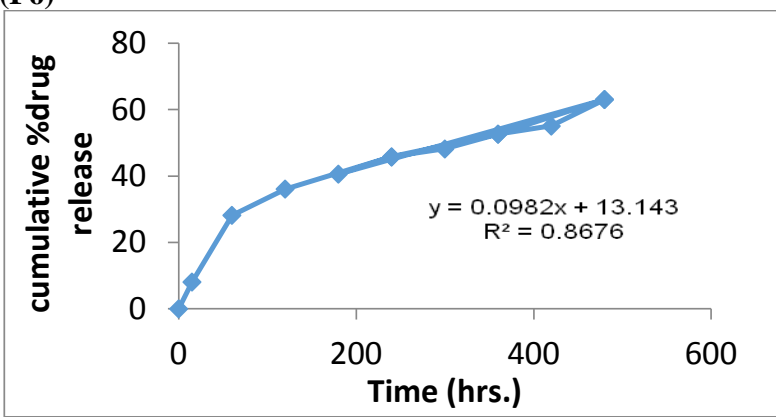

Figure 22: Drug Release Kinetics First Order Formulation

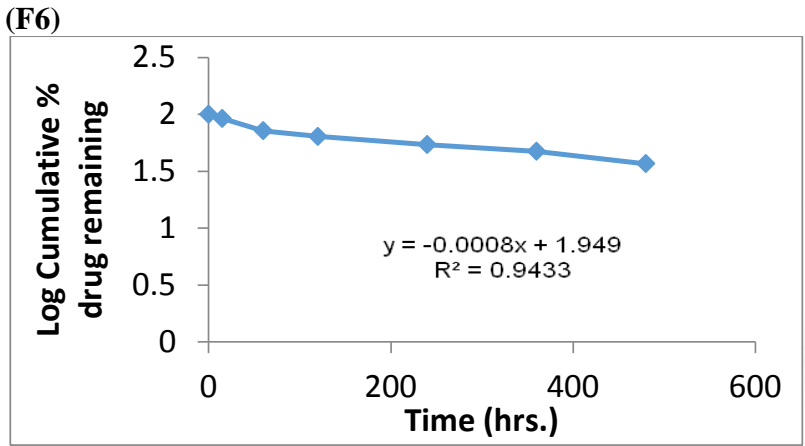

Figure 23: Drug Release Kinetics Higuchi Formulation

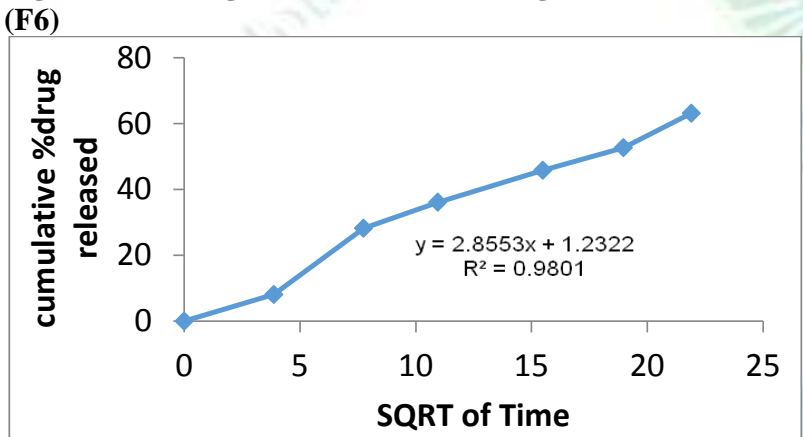

Figure 24: Drug Release Kinetics Kors-Peppas Formulation (F6)

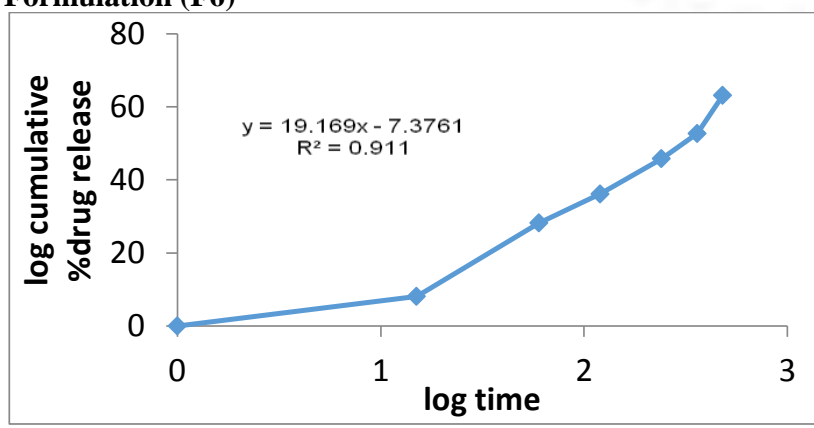

Permeation study

\section{In vitro permeation study}

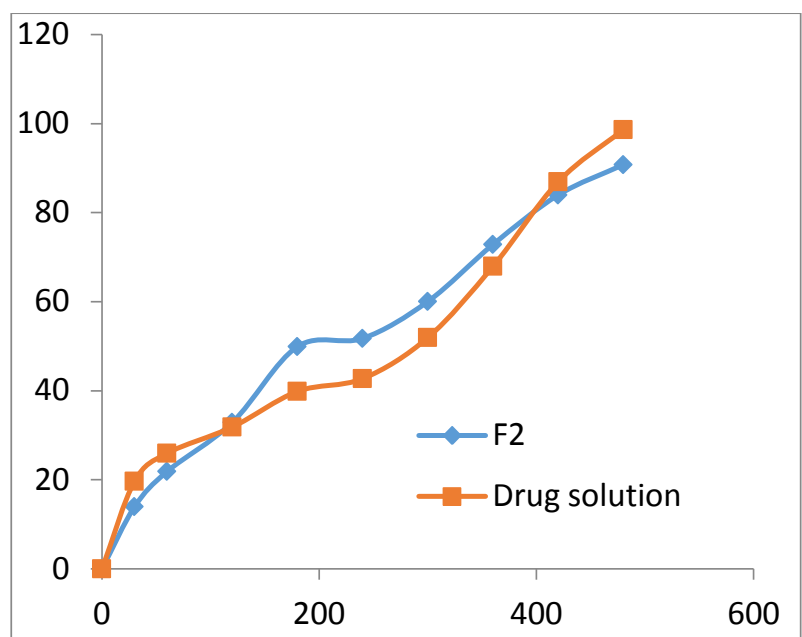

Permeation of selected batch (F2) compare to drug solution.

Ex vivo permeation carried out by using nasal mucosa of goat and permeation profile shown in the above figure.

\section{Stability studies}

All the formulation showed good stability at $27{ }^{\circ} \mathrm{C} / 60$ $\%$ RH. There were no significant changes in visual appearance and clarity; $\mathrm{pH}$ remained constant for entire stability period; drug content did not deviate by than $2 \%$ indicating that the drug is stable in the in situ gel formulations and also there was no significant variation in the in vitro release studies at the end of 30 day period. A formulation intended for a nasal administration, if prepared as a solution should not show precipitation of the drug present in it for long periods of storage. This is achieved when formulations were stored at normal room temperatures not exceeding $32{ }^{\circ} \mathrm{C}$. The formulation when stored under refrigerated conditions showed settling of the polymer and also the viscosity of the formulation increased. The formulations when stored at $45{ }^{\circ} \mathrm{C} / 75 \% \mathrm{RH}$, the formulations remained as a gel for long duration. 


\section{REFERENCES}

1. Kute JU, Darekar AB, Saudagar RB. A Review: In-Situ GelNovel Approach for Nasal Delivery. World journal of pharmacy and pharmaceutical sciences, 2013; 3(1): 187- 203.

2. Dhakar RC, Maurya SD, Saluja V. From formulation variables to drug entrapment efficiency of microspheres: A technical review, Journal of Drug Delivery \& Therapeutics. 2012; 2(6):128-133

3. Kapoor D, Patel M, Vyas RB, Lad C, Lal B, Site specific drug delivery through nasal route using bioadhesive polymers, Journal of Drug Delivery and Therapeutics. 2015; 5(1):1-9

4. Chien YW, Su KS, Chang SF. A text book of Anatomy and physiology of the nose. In Nasal Systemic Drug Delivery: Drugs and the Pharmaceutical Sciences. New York: Marcel Dekker; 1989, p.1-26.

5. Prajapati SK, Kumar S, Sahu VK, Prakash G, Proniosomal gel of flurbiprofen: formulation and evaluation, Journal of Drug Delivery and Therapeutics; 2012; 2(1):1-5

6. Patel H, Patel P, bhatt TB, Suthar M, In Situ Gelling System: A Review, J. Chem. Pharm. Res, 2011; 3(6):217-221.

7. Nirmal HB, Bakliwal SR, Pawar SP, In-Situ gel: New trends in Controlled and Sustained Drug Delivery System. International Journal of Pharm Tech Research; 2010; 2(2):1398-1408.

8. Allen C, 2001. Rizatriptan: clinical update. In: The triptans: novel drugs for migraine. Humphrey, P., Ferrari, M., Olesen, J., (eds). New York: Oxford University Press; 2001; 1:199. 205.

9. Anthony CM, Osserton MD, Widdip B, In: Clark's analysis of drugs and poison. Regis, L. Borset (eds). London; 2004; $1: 1540$.

10. Sanders-Bush S, Mayer SE, 5-Hydroxytryptamine (serotonin): Receptor agonists and antagonists. In: The pharmcological Basis of Therapeutics. Goodman, Gillman, Hardman, J. G., Limbard, L. E., (eds). New York: Mc Graw-Hill; 2001: 278281.

11. Hargreaves RJ. Pharmacology and potential mechanisms of action of rizatriptan. Cephalalgia; 2000; 20, 2-9.

12. Nisha GS, Maithil P, Charyulu RN. Formulation and Development of Nasal in Situ Gels of Triptans for Anti
Migraine Activity. International Journal of Research in Pharmaceutical and Biomedical Sciences. 2012; 3(2):862-870.

13. Ricci EJ, Bentley MVLB, Farah M, Bretas RES, Marchetti JM. Rheological characterization of Poloxamer 407 lidocaine hydrochloride gels. Eur J Pharm Sci 2002; 17:161-167.

14. Balasubhramanian J, Kant S, Pandit JK, Acta . Pharm., 2003; 53: 251-261.

15. Gibert JC, Richardson JL, Davies MC, Palin KJJ, Controlled Release. 1996; 5:173-181.

16. Shinde JV, Mali KK, Dias RJ, Havaldar VDand Mahajan NS. In-situ Mucoadhesive Nasal Gels of Metoclopramide hydrochloride: Preformulation and Formulation Studies. Journal of Pharmacy Research. 2008; 1(1):88-96.

17. Pisal SP, Paradkar AR, Mahadik KR, Kadam SS. Pluronic gels for nasal delivery of Vitamin B12. Part I: Preformulation study. Int J Pharma 2004; 270:37-45.

18. Choi H.K., Jung J.H., Ryu J.m., Yoon S.J., Oh Y.K., And Kim C.K., Development of in situ gelling and mucoadhesive acetaminophen liquid suppository. Int. J. Pharm. 1998; 165:33- 44

19. Rheological characterization of Poloxamer 407 lidocaine hydrochloride gels. Eur J Pharm Sci 2002; 17:161-167.

20. Mahajan HS and Gattani SG. Gellan Gum Based Microparticles of Metoclopromide hydrochloride for Intranasal Delivery: Development and Evaluation. Chem. Pharm. Bull. 2009; 57(4): 388-392.

21. Yong CS, Cho JS, Quan QZ, Rhee JD, Kim CK et al. Effect of sodium chloride on Gelation temperature temperature, gel strength and bioadhesive force of poloxamer gels containing diclofenac sodium", Int. J. Pharm., 2001; 226:195-205.

22. Majithiya RJ, Ghosh, PK and Umrethia, ML, Thermoreversible mucoadhesive gel for nasal delivery of sumatriptan, AAPS PharmSciTech, 2006; 7:E1-E7.

23. Singh S, Drug stability testing and shelf life determination according to international guidelines, Pharm Tech., 1999; 7:69-79.

24. Pramod et al. Development of Zolmitriptan Gel for Nasal Administration. Asian J Pharm Clin Res, 2012; 5(3):88-94. 